\title{
Notes on transcription and translation
}

This study aims at allowing the voices of seventeenth-century Benedictine nuns to be heard; it therefore presents quite a number of quotations from a variety of manuscripts. Editorial policy has been to render the manuscripts as faithfully as possible, resorting to editorial interventions only when the original text proved potentially confusing. All spelling, including capitalisation, is as in the original, except for the following:

- the use of $i$ and $v$ has been modernised to $j$ and $u$ where necessary

- archaic contractions (such as $\mathrm{y}^{\mathrm{e}}, \mathrm{y}^{\mathrm{t}}$ or $\mathrm{w}^{\mathrm{n}}$ ) have been silently expanded

- punctuation has been altered when it was entirely lacking or, on the contrary, when it was so abundant that it obscured the meaning of the sentence.

Translations from French manuscripts are by the author. 